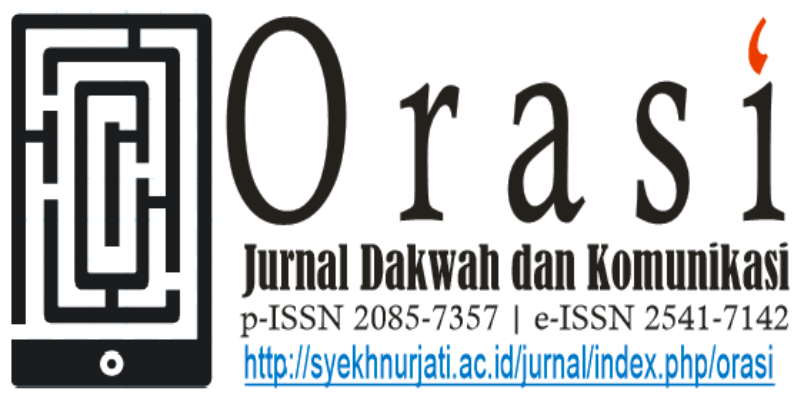

Volume 12 No. 2 Desember 2021

\title{
CITRA KULINER LOKAL IKLAN KECAP BANGO SERI MEAT DIAGRAM: KAJIAN SEMIOTIKA PEIRCE
}

\section{LOCAL CULINARY IMAGE OF KECAP BANGO ADVERTISEMENT MEAT DIAGRAM SERIES: PEIRCE'S SEMIOTIC ANALYSIS}

\author{
Arif Ardy Wibowo ${ }^{1, a)}$, Ulaya Ahdiani' ${ }^{2}$, Rahina Nugrahani ${ }^{3}$ \\ ${ }^{1}$ Prodi Ilmu Komunikasi Universitas Ahmad Dahlan, \\ ${ }^{2}$ Prodi Sastra Inggris, Universitas Ahmad Dahlan, \\ ${ }^{3}$ Prodi Desain Komunikasi Visual, Universitas Negeri Semarang \\ a)e-mail:arif.wibowo@comm.uad.ac.id
}

\begin{abstract}
ABSTRAK
Kecap Bango sebagai salah satu produk yang memakai iklan yang unik, selalu berupaya untuk mengedepankan budaya lokal sebagai unsur yang harus ada dalam iklan mereka. Budaya lokal ini dikemas menggunakan media kuliner sehingga akan lebih menarik sekaligus mengkampanyekan budaya lokal asli Indonesia. Penelitian ini bertujuan untuk mengungkap makna dibalik visual dengan membaca tanda yang tersaji dalam sebuah iklan. Proses yang dilakukan yaitu analisis data diuraikan dengan pendekatan deskriptif kualitatif. Penelitian meliputi pengumpulan berbagai data dari subjek penelitian dan sumber yang relevan. Kemudian data dianalisis untuk mendapatkan pemahaman tentang objek kajian yang dihadapi. Beberapa kegiatan dalam penelitian ini adalah mengumpulkan data dengan cara observasi. Kemudian memilah dan menganalisa data. Kemudian diakhiri dengan membuat kesimpulan dari penelitian ini. Hasil dari penelitian ini dengan penguatan citra budaya lokal yang disampaikan oleh iklan Kecap Bango seri Meat Diagram. Analisis menggunakan kajian semiotika C.S Pierce mengerucut pada bagian indeks, ikon dan simbol pada iklan. Analisis yang didapat yakni mengungkap konstruksi tanda yang ada dibalik visual sebuah iklan, khususnya yang terkait dengan budaya kuliner lokal yang ada pada iklan Kecap Bango seri Meat Diagram.
\end{abstract}

Kata Kunci: Iklan, Kecap Bango, Semiotik 


\begin{abstract}
Kecap Bango as a product that uses unique advertisements always strives to accentuate local culture as a mandatory element in their ads. This local culture is packaged using culinary media so that it will be more attractive and, at the same time, campaign for local Indonesian cultures. This study aims to reveal the meaning behind the visuals by analyzing the signs hidden in Kecap Bango's ads. The data analysis process was carried out by describing the signs with applying a qualitative descriptive approach. The study included collecting various data from research subjects and relevant sources. Then the data were analyzed to get an understanding of the object of the study at hand. Some steps in this research were collecting the data by conducting an observation, sorting them and analyzing them. Then, the study ended with making a conclusion from this research. Results of this study were to strengthen the local cultural images conveyed by Kecap Bango Meat Diagram advertisement series. The analysis applied C.S Pierce's semiotic theory to focus on the index, icon, and symbol sections of the ad. The analysis revealed the sign construction behind the visuals of the ads, especially those related to the local culinary cultures in Kecap Bango's Meat Diagram series ads.
\end{abstract}

Keywords: Advertising, Kecap Bango, Semiotic

\section{Pendahuluan}

Iklan atau advertisement merupakan salah satu cara sebuah perusahaan dalam mempromosikan dan menarik minat dari konsumen produknya. Dalam bukunya, Erlhoff (2007) menyatakan, sebuah iklan merupakan representasi yang dirancang untuk mempengaruhi dan memberitahu pada pasar, apa saja yang dibutuhkan juga diinginkan melalui sebuah media yang bertujuan pada lakunya sebuah produk. Menurut Belch and Belch (2004), iklan merupakan wujud yang dirancang secara sengaja dan rasional, mempertimbangkan aspek logis konsumen dalam proses pengambilan keputusan, serta pada aspek lain mencoba menyentuh secara emosional. Sebuah iklan yang efektif adalah sebuah iklan yang menggabungkan alasan praktis untuk membeli produk dengan nilainilai emosional. Dengan menyentuh nilai emosional, maka konsumen akan menjadi loyal terhadap sebuah produk. Menurut Hartono dan Sugalih (2019), iklan adalah sebuah pesan yang ingin disampaikan. Pesan tersebut berupa tanda yang memiliki makna. Iklan juga menjadi salah satu bentuk komunikasi visual yang berisi berbagai konsep tanda atau makna. Konsep tanda atau makna tersusun dalam struktur teks iklan yang dapat dilihat dan ditentukan dengan menggunakan pola interpretasi.

Indonesia yang merupakan salah satu surga kuliner yang ada di dunia, memiliki berbagai olahan khas yang tersebar di berbagai daerah dengan corak rasa yang khas dan otentik. Rendang salah satunya, sempat mencuri perhatian dunia ketika dinobatkan menjadi makanan terenak di dunia versi CNN tahun 2017 (Tim Cheung 2017). Selain rendang, ternyata ada lebih dari 10 jenis makanan Indonesia yang mendunia. Maulana dan Prasetia (2015) dalam artikelnya 
mengatakan bahwa selain rendang, makanan lain seperti sate, bakso, nasi goreng, soto, gado-gado atau ketoprak, nasi uduk, pempek, siomay, gudeg, martabak, nasi kuning, serta es dawet dan es campur, adalah kuliner local Indonesia yang banyak digemari oleh masyarakat asing, terutama saat mereka berkunjung ke Indonesia.

Kuliner yang ada di Indonesia memiliki keunggulan dibanding beberapa negara tetangga di Asia Tenggara. Besra (2012) menjelaskan adanya percampuran budaya asing dengan budaya lokal. Tidak akan menemukan kesulitan dalam mencari citarasa yang sesuai dengan lidah karena masakan Indonesia memiliki sangat banyak pilihan, mulai dari pedas, asin, manis serta bahan yang beragam mulai dari ikan, daging, sayur semuanya dapat ditemukan pada kuliner Indonesia.

Meskipun kuliner lokal sangat beragam, tentunya tetap membutuhkan adanya pengenalan dan promosi sehingga akan tetap dicari oleh para penikmatnya. Promosi dapat dilakukan dengan beberapa cara. Tabula Rasa merupakan salah satu cara promosi kuliner dengan menggunakan media film. Lukitasari (2019) menyatakan bahwa setelah menonton film Tabula Rasa, para penonton akan sepakat jika makanan dalam film ini sangat menggugah selera makan. Selain itu, film ini mengetengahkan proses memasak khas Indonesia, yang kental dengan proses menghaluskan bumbu, tungku tradisional serta perjalanan sebuah makanan sebelum disantap.
Kecap Bango sebagai produk yang senantiasa mengangkat kuliner lokal sebagai bagian kampanyenya juga memegang peranan penting dalam promosi masakan yang ada di tiap daerah. Secara konsisten sejak tahun 2005, Kecap Bango selalu menghadirkan masakan nusantara dalam acara Festival Jajanan Bango. Acara tersebut, selain sebagai wujud nyata pelestarian makanan asli Indonesia, juga sebagai dukungan adanya regenerasi penjaja kuliner di Indonesia (Bango Warisan Kuliner, 2019)

Strategi pemasaran yang dilakukan oleh Kecap Bango sangat beragam. Pada strategi internal, Kecap Bango menggunakan logo, packaging, typografi, maupun tagline. Sementara, strategi eksternal, ada pemasaran di mana terdapat iklan melalui baliho, banner, media baru, media cetak dan media konvensional. Selain itu, Kecap Bango juga sangat memperhatikan strategi melalui supplier, distributor, dan antar kompetitor (Sampurna et al. 2020)

Iklan produk Kecap Bango yang selama ini ada di publik, selalu mempunyai keunikan masing-masing. Dari sekian banyak kampanye yang dilakukan oleh merek Bango, ada sebuah kampanye yang dipandang sangat menarik kacamata kajian semiotika. Kajian ini, tentunya sangat berguna bagi para produsen iklan sebelum membuat karyanya. Menggunakan semiotika, iklan yang dibuat tentu akan lebih berbobot karena mempunyai nilai-nilai yang tersembunyi dibalik visual yang ditampilkan. Tentunya, dengan makin berbobotnya iklan yang ada di Indonesia akan 
turut memajukan dunia periklanan Indonesia. Iklan produk Kecap Bango yang akan menjadi objek penelitian adalah iklan Kecap Bango seri Meat Diagram. Iklan dengan mengangkat cita rasa lokal ini, merupakan salah satu wujud kepedulian terhadap warisan budaya Indonesia. Seperti halnya batik dan tarian, kuliner merupakan salah satu cara nenek moyang kita dalam mewariskan kekayaan dari bumi Indonesia.

\section{Metodologi Penelitian}

Penelitian ini dilakukan secara kualitatif dengan pendekatan studi kasus. Studi kasus merupakan sebuah analisis yang mana peneliti melakukan analisis mendalam dalam sebuah kasus yang dapat berupa program, aktivitas, proses dan sebagainya (Creswell and Creswell 2018).

Teknik pengumpulan data dokumen umumnya menggunakan data sekunder. Dalam kasus penelitian ini, data diperolah dari website http://www.adeevee.com/. Website ini merupakan sebuah wadah untuk menampung seluruh hasil karya periklanan dari seluruh dunia, sehingga memuat banyak content tentang periklanan yang memadai. Proses dalam pengumpulan data dokumen, perlu adanya kehati-hatian terkait dengan keabsahan data, sehingga tidak ada distorsi dari teks ataupun visual yang diperoleh (Rohidi 2011). Sampel dalam penelitian ini merupakan Iklan Kecap Bango seri Meat Diagram yang diluncurkan oleh Kecap Bango sebagai salah satu promosi masakan nusantara.
Analisis data menggunakan teori semiotika Charles Sanders Peirce. Merujuk pada teori Peirce, 3 elemen utama dalam metode analisisnya, diantaranya adalah representament, object dan interpretant (Piliang 2012). Metode analisis yang dikembangkan oleh Pierce ini terdiri dari teori segitiga yang terdiri dari representament, object dan interpretant yang kesatuan dari tiga elemen ini akan membangun sebuah tanda. Secara sederhana dapat dilihat dari bagan berikut :

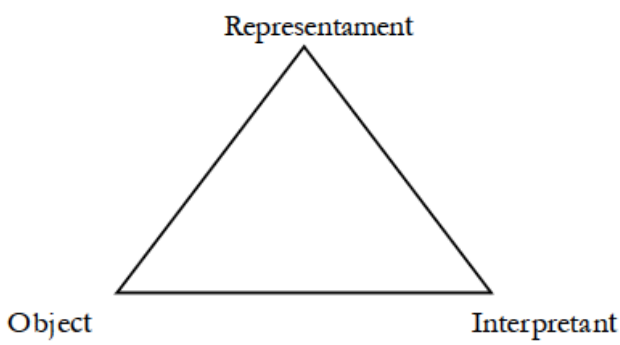

Bagan 1. Model Segitiga C.S Pierce

Dengan menggunakan analisis kajian semiotika Pierce ini, akan diungkap tanda yang ada pada objek visual sebuah iklan. Analisis semiotika Pierce ini diharapkan dapat mengupas sebuah iklan, sehingga dapat dimengerti oleh orang awam dan pesan yang dimaksud dalam promosi produk tersebut akan lebih mudah tersampaikan. Proses pemaknaan tanda yang mengikuti skema ini disebut sebagai proses semiosis. tanda menjadi wakil yang menjelaskan sesuatu bahwa makna sebuah tanda dapat berlaku secara pribadi, sosial, atau bergantung pada konteks tertentu dan bergantung pada orang yang memaknai juga latar belakang masing-masing. 


\section{Hasil dan Pembahasan}

Masyarakat Indonesia mengkonsumsi semua bagian daging sapi, kambing dan ayam. Mereka makan iga dan lidah sapi, kepala dan cakar ayam, otak kambing, usus dan lainnya. Tantangan selalu ada tentang bagaimana memasak berbagai bagian ini menjadi makanan yang lezat. Berdasarkan hasil analisis visual dari 3 iklan Kecap Bango, didapatkan 39 jenis masakan yang merupakan kreasi dari berbagai daerah. Masakan - masakan tersebut beberapa merupakan kuliner khas sebuah daerah, namun juga ditemukan beberapa kreasi yang dapat ditemukan di daerah lain dikarenakan kesamaan cara olahan dan resep tersebut sudah dikenal oleh orang banyak. Berikut hasil dari analisis visual yang telah diperoleh dalam penelitian ini;

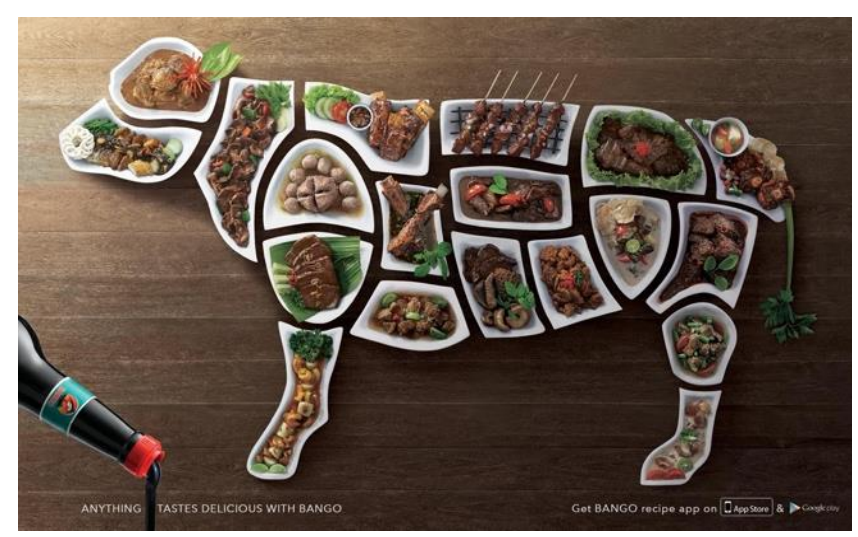

Gambar 1. Beef Diagram

Sumber : (adeevee 2014)

Iklan yang pertama berjudul Beef

Diagram, terdiri dari 3 tanda terdiri dari 2 ikon dan 1 simbol. Ikon yang pertama merupakan sebuah penggambaran bentuk sapi yang tersusun atas piring-piring putih diatas meja. Ikon yang kedua berupa sajian makanan khas nusantara yang diolah dari tubuh sapi itu sendiri.
Proses semiosis yang diawali oleh penggambaran bentuk sapi pada iklan ini yang terbentuk oleh penataan piring-piring putih (R), yang merupakan representasi dari objek iklan itu sendiri yang terdiri dari masakan dengan bahan dasar daging sapi (O). Relasi antara Representament $(\mathrm{R})$ dengan $\operatorname{Object}(\mathrm{O})$ membentuk Interpretant (I) yang menjelaskan bahwa ada 19 piring yang disusun dan seluruh hidangan makanan itu membentuk seekor sapi ini, merupakan kuliner nusantara dengan bahan dasar daging sapi. Itulah yang menjadi alasan piring-piring berisi makanan ini disusun sehingga membentuk seekor sapi yang juga berbahan utama daging sapi, dikarenakan sapi merupakan salah satu bahan olahan utama yang ada pada masakanmasakan yang ada pada iklan ini.

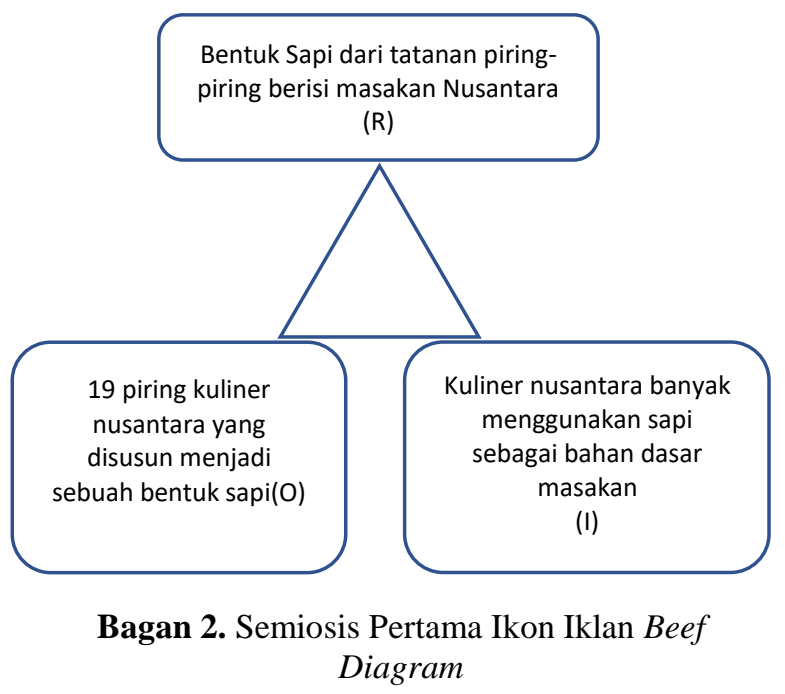

Proses semiosis yang kedua terbentuk dari detil masakan yang ada pada masingmasing piring putih (R), yang merupakan representasi dari objek kuliner khas nusantara yang berasal dari berbagai daerah (O). Relasi antara Representament $(\mathrm{R})$ dengan Object $(\mathrm{O})$ membentuk Interpretant (I) yang menjelaskan bahwa masakan yang tersaji menggunakan 
bahan dasar sapi, dan disesuaikan antara piring dan bahan makanan itu. Misal pada bagian mulut sapi terdapat Rujak Cingur asal Surabaya, dan bahan utama dari Rujak Cingur ini merupakan daging dari mulut sapi. Begitu juga dengan bagian lain, seperti Sop Kaki, Iga Bakar, Sop Buntut, Babat Gongso yang menyesuaikan letak darimana daging itu diambil dari seekor sapi. Setiap daerah memiliki olahan khas dari tiap bagian tubuh sapi dan menghasilkan citra kuliner lokal yang khas.

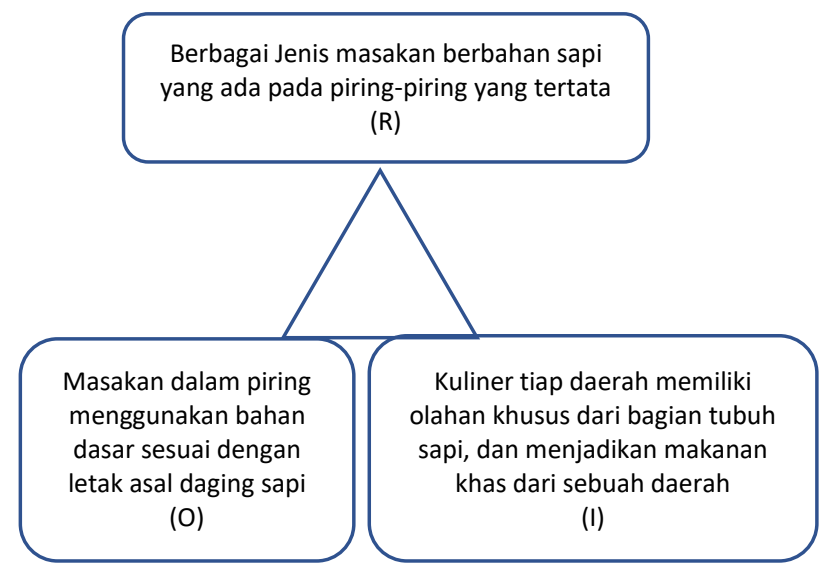

Bagan 3. Semiosis Ikon Iklan Beef Diagram

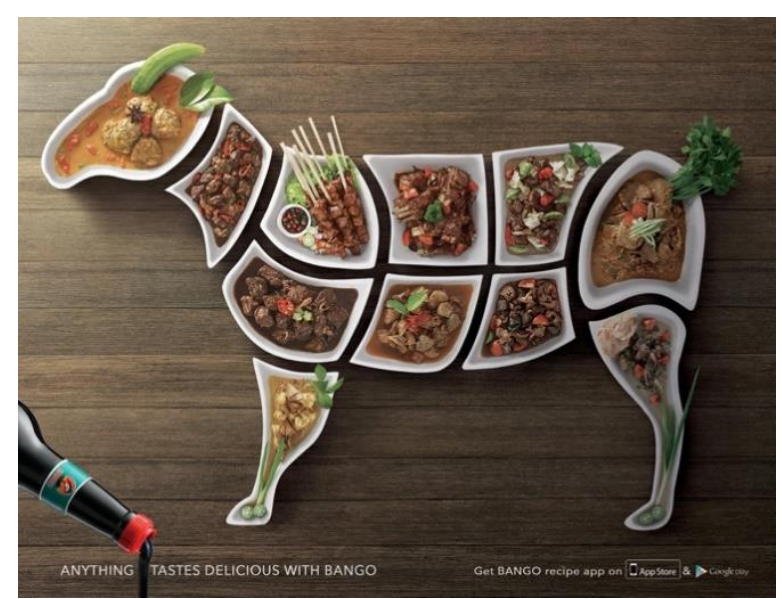

Gambar 2. Mutton Diagram Sumber : (adeevee 2014)

Iklan kedua berjudul Mutton Diagram yang masih senada dengan iklan yang pertama. Semiosis pada iklan Mutton
Diagram diawali oleh penggambaran bentuk kambing dari penataan piring-piring putih (R), sama seperti iklan sebelumnya yang merupakan representasi dari objek iklan yakni dengan bahan dasar daging sapi (O). Relasi antara Representament $(\mathrm{R})$ dengan $\operatorname{Object}(\mathrm{O})$ membentuk Interpretant (I) menjelaskan bahwa 11 piring makanan itu merupakan kuliner nusantara dengan bahan dasar daging kambing, sehingga disusun seperti bentuk seekor kambing. Ikon kambing tersebut merupakan tanda 11 makanan ini berbahan dasar daging kambing.

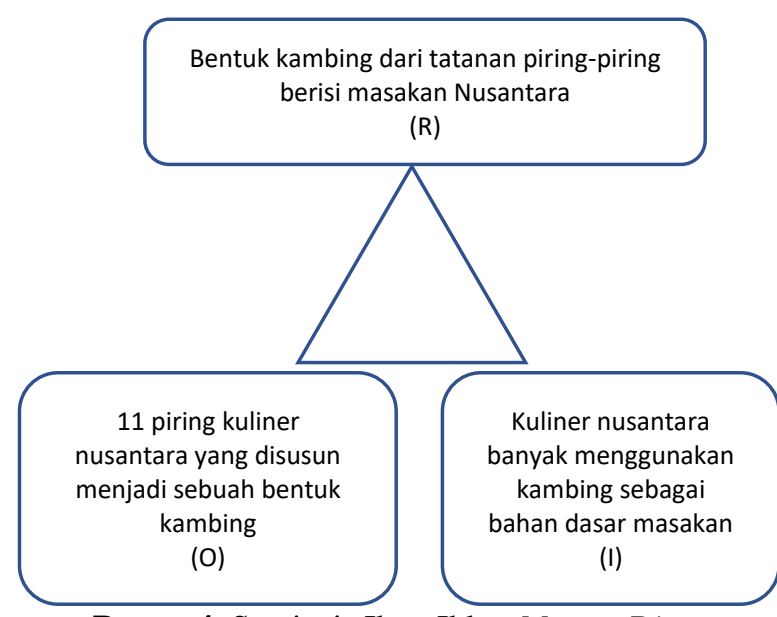

Bagan 4. Semiosis Ikon Iklan Mutton Diagram

Semiosis yang kedua terbentuk dari masakan yang ada pada masing-masing piring putih (R), yang merupakan representasi dari objek kuliner khas nusantara yang berasal dari berbagai daerah dengan bahan kambing (O). Relasi antara Representament (R) dengan Object (O) membentuk Interpretant menyatakan jika makanan seperti Rabeg dari Banten dan Tengkleng Kikil menggunakan daging yang berasal dari bagian perut dan kaki kambing, persis seperti peletakan piring yang seolah menjadi perut dan kaki kambing. Seperti halnya sapi, iklan ini juga 
menampilkan daerah yang khas dengan olahan kambingnya.

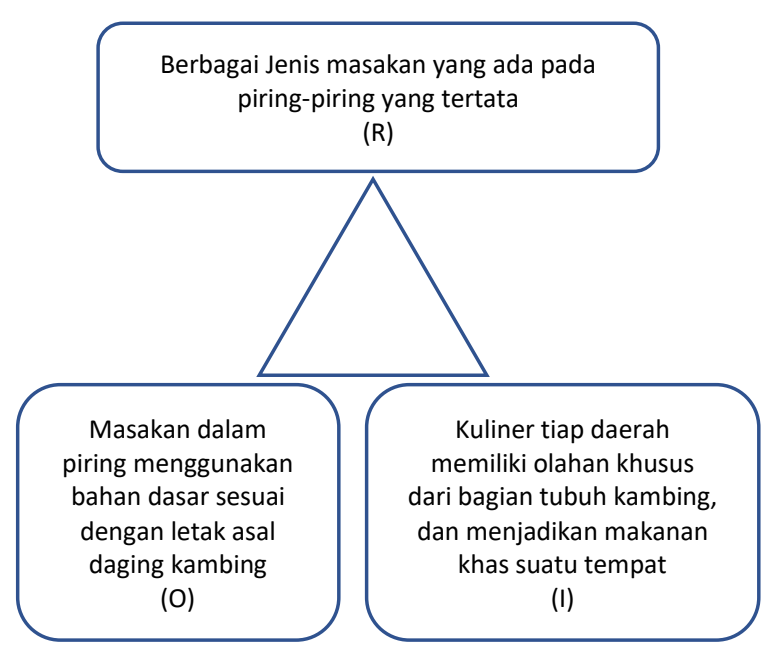

Bagan 5. Semiosis Ikon Iklan Mutton Diagram

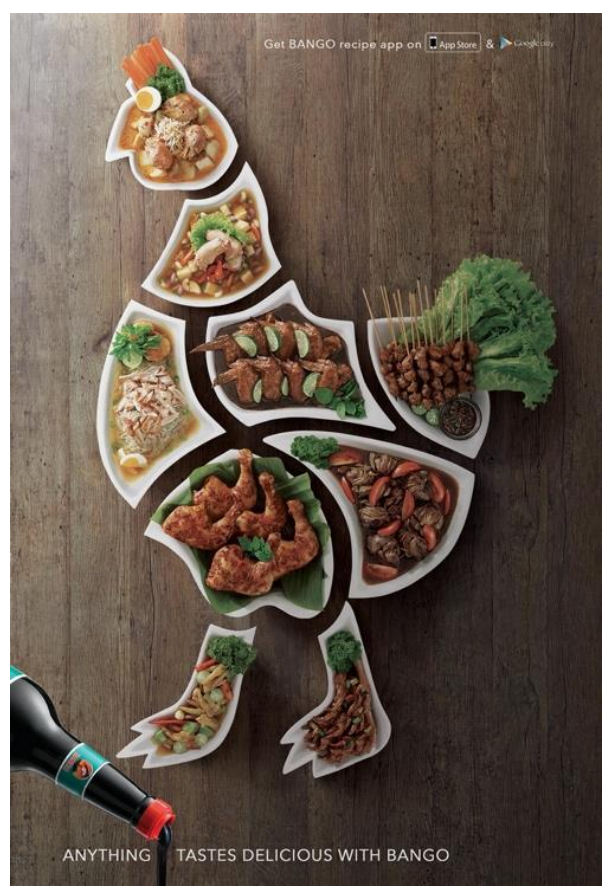

Gambar 3. Chicken Diagram

Sumber : (adeevee 2014)

Iklan ketiga berjudul Chicken Diagram, diawali oleh penggambaran bentuk dari seekor ayam pada iklan ini yang dibentuk melalui penataan piring-piring putih (R), yang merupakan representasi dari objek iklan itu sendiri yang terdiri dari masakan berbahan daging ayam (O). Relasi antara Representament (R) dengan Object (O) membentuk Interpretant (I) yang menjelaskan bahwa ada 9 piring yang tertata dan isi dari piring tersebut berisi hidangan berasal dari bahan ayam yang membentuk gambar ayam pula. Alasan piring-piring berisi makanan ini disusun sehingga membentuk seekor ayam dikarenakan daging ayam merupakan salah satu bahan olahan utama yang ada pada masakan-masakan yang ada pada iklan ini.

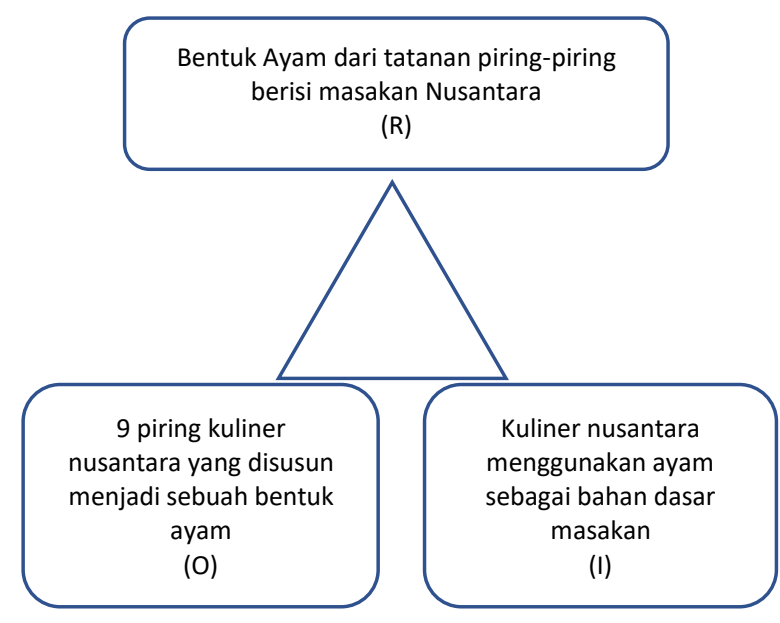

Bagan 6. SemiosisIkon Iklan Chicken Diagram

Proses semiosis selanjutnya merupakan bentukan dari detil masakan yang ada pada masing-masing piring putih (R), yang merupakan representasi dari objek kuliner khas nusantara yang berasal dari berbagai daerah (O). Relasi antara Representament (R) dengan Object $(\mathrm{O})$ membentuk Interpretant (I) yang menjelaskan bahwa masakan yang ada pada 9 piring tersebut merupakan hasil olahan dengan bahan daging ayam, tidak hanya itu peletakan juga disesuaikan antara piring dan bahan makanan itu. Misal pada bagian kepala terdapat Soto Bongko yang 
merupakan khas Sumedang, dan bahan utama dari Rujak Cingur ini merupakan otak ayam. Begitu juga dengan bagian lain, Krewedan dan Kaki Ayam masak Pindang dari Jawa Tengah dan Palembang menyesuaikan letak darimana daging itu diambil dari seekor ayam.

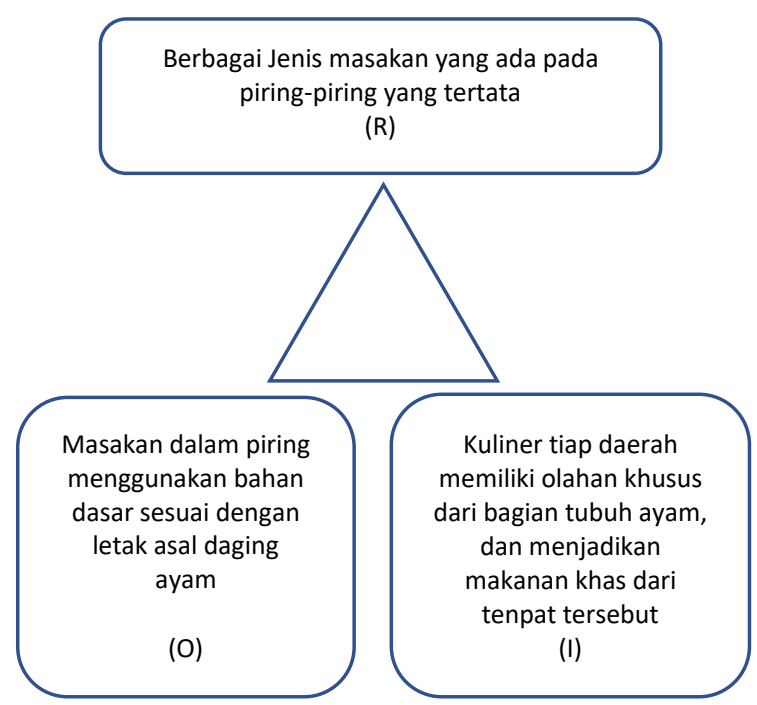

Bagan 7. Semiosis Ikon Iklan Chicken Diagram

Kesamaan dari 3 iklan ini merupakan semiosis simbol yang terbentuk dari botol kecap yang menuangkan isinya disertai kalimat "anything tastes delicious with Bango". Pembentukan simbol dari terbentuk dari visual botol kecap yang sedang menuangkan isinya disertai kalimat "Anything Tastes Delicious with Bango" (R), yang merupakan representasi dari Kecap Bango yang selalu ada dalam setiap masakan pada iklan tersebut (O). Relasi antara Representament (R) dengan Object (O) membentuk Interpretant (I) yang menjelaskan bahwa Kecap Bango, akan selalu menjadikan masakan menjadi lebih lezat pada tiap masakan yang dibuat, namun juga sebagai penegasan bahwa Kecap Bango merupakan salah satu penjaga warisan kuliner nusantara.

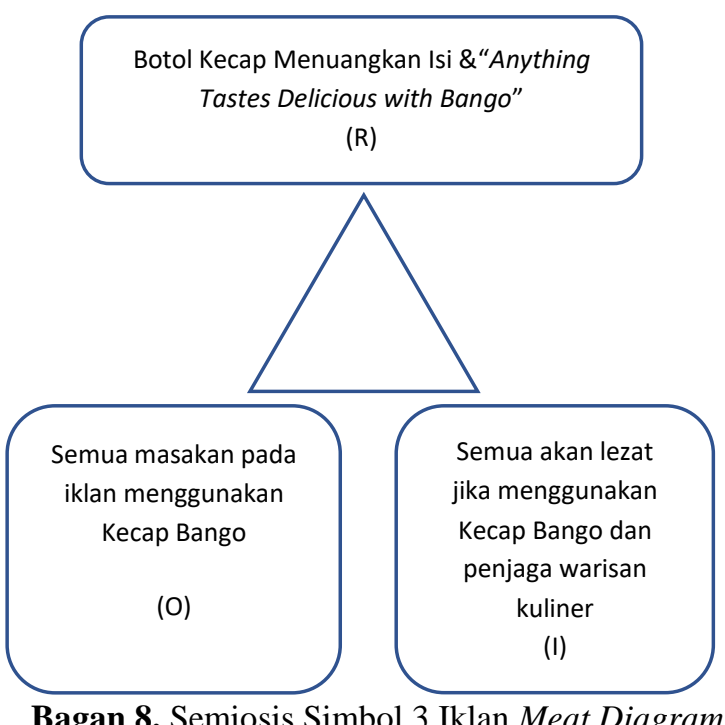

Bagan 8. Semiosis Simbol 3 Iklan Meat Diagram

\section{Simpulan dan Saran}

Berdasarkan kajian Semiotika yang sudah dilakukan pada pembahasan, hasil analisis dari ketiga iklan ini adalah terjadi pada kuliner lokal yang ada di nusantara menjadi objek utama dalam visual iklan. Total terdapat 39 jenis kuliner lokal yang menjadi objek dalam ketiga iklan Kecap Bango seri Meat Diagram. Melalui kajian analisis Semiotika Peirce, didapatkan bahwa tiap iklan masingmasing memiliki proses semiosis sebanyak 3 kali, yang terdiri dari 2 pembentukan ikon dan 1 simbol. Gambar Sapi, Kambing dan Ayam merupakan hasil semiosis yang pertama sebagai wujud representasi dari bahan utama pada tiap tiap masakan yang dihadirkan pada iklan tersebut. Semiosis kedua dibentuk melalui detil serta letak tiap masakan pada bagian tubuh tertentu baik dari Sapi, Kambing dan Ayam. Setiap bagian tubuh Sapi, Kambing dan Ayam dapat diolah menjadi makanan khas yang menjadi ikon sebuah daerah seperti Rendang (Sumatera Barat), Rujak Cingur (Surabaya), Empal (Sunda), Sop Konro (Makassar), Rabeg (Banten), Kambing 
Krewedan (Jawa Tengah), Ayam masak

Pindang (Palembang), Semur dan

Krengsengan (Jawa Tengah). Tiap masakan ini menggunakan bagian tertentu dari Sapi,

Kambing atau Ayam dalam membuat masakan

khas daerah masing-masing, sehingga daerah tersebut menjadi ikut terkenal oleh karakter makanan yang dihasilkan.

Simbol yang dihasilkan dari analisis terbentuk dari botol kecap yang sedang menuangkan isinya dengan tagline "Anything Tastes Delicious with Bango" yang merupakan bahwa semua masakan dalam iklan tersebut, memakai Kecap Bango dalam proses pembuatan ataupun penyajian. Kecap Bango merupakan kecap yang mendukung kuliner nusantara dibuktikan dengan semua masakan yang hadir dalam iklan ini merupakan hasil karya kuliner lokal. Selain itu Kecap Bango dalam iklan tersebut menyajikan semua kuliner lokal sebagai wujud penegasan bahwa Kecap Bango merupakan salah satu penjaga citra kuliner lokal dengan selalu menampilkan masakan nusantara dalam berbagai promosi yang dilakukan.

Saran yang mungkin dapat disajikan dalam tulisan ini adalah Makin majunya teknologi menuntut makin adanya kreatifitas dalam pembuatan iklan, baik secara visual maupun secara makna yang terkandung di dalamnya. Sebuah iklan akan banyak menarik penonton jika secara visual terlihat menggoda terlebih jika yang disajikan adalah berupa makanan. Sebuah iklan makanan seperti yang ditampilkan oleh Kecap Bango seri Meat Diagram terlihat sangat menarik dengan ikon sapi, kambing dan ayam sebagai bahan dasar masakan. Selain itu, adanya makna dibalik visual yang disimbolkan dengan tanda tanda, akan memperkuat sebuah iklan selain visual yang memikat. Kajian konsep tanda ini, tentunya sangat berguna bagi para produsen iklan sebelum membuat karyanya. Menggunakan kajian tanda, iklan yang dibuat tentu akan lebih berbobot karena mempunyai nilai-nilai yang tersembunyi dibalik visual yang ditampilkan. Tentunya, dengan makin berbobotnya iklan yang ada di Indonesia akan turut memajukan dunia periklanan Indonesia.

\section{Daftar Pustaka}

Adeevee. 2014. "Bango: Meat Diagram Cow, Meat Diagram Sheep, Meat Diagram Chicken." http://www.adeevee.com/2014/10/bangomeat-diagram-cow-meat-diagram-sheepmeat-diagram-chicken-outdoor-print/.

Bango Warisan Kuliner. 2019. “ADA APA DI \#FJB2019."

https://www.bango.co.id/fjb2019.

Belch, George E, and Michael A Belch. 2004. "Advertising and Promotion: An Integrated Marketing Communications Perspective 6th." New York: McGraw-Hil L.

Besra, Eri. 2012. "Potensi Wisata Kuliner Dalam Mendukung Pariwisata Di Kota Padang." Jurnal Riset Akuntansi Dan Bisnis 12 (1): 74-101.

Creswell, J.W., and J. David Creswell. 2018. Research and Design Qualitative, Quantitative and Mixed Methods Approaches. Thousand Oaks California. 5th ed. California: SAGE PUBLICATIONS, INC.

Erlhoff, Michael. 2007. Design Dictionary: Perspectives on Design Terminology. Edited by Timothy Marshall. Berlin: Walter de Gruyter.

Hartono, Dudi, and Asep Sugalih. 2019. "Makna Simbol Senyum Pada Iklan Lay' S Di Televisi (Semiotics Analyisis of Charles Sanders Pierce)." Jurnal Perspektif Komunikasi 3 (1): 39-49. 
Lukitasari, Rimalinda. 2019. "Penguatan Reputasi Masakan Padang: Simbol Promosi Pariwisata Gastronomi Dalam Film Tabula Rasa." Jurnal Master Pariwisata (JUMPA) 6 (1): 124.

doi:https://doi.org/10.24843/JUMPA.2019.v0 6.i01.p01.

Maulana, Imam, and Arus Reka Prasetia. 2015. "Strategi Kreatif Usaha Kuliner Indonesia Untuk Memperluas Pasar Ke Kawasan Asia Tenggara Dalam Era Masyarakat Ekonomi Asean (Mea)." Seminar Nasional Strategi Indonesia Kreatif Menghadapi ASEAN Economic Community 2015, 170-84. doi:10.13140/RG.2.1.3886.8563.

Piliang, Yasraf Amir. 2012. Semiotika Dan Hipersemiotika: Kode, Gaya \& Matinya Makna. Matahari.

Rohidi, Tjetjep Rohendi. 2011. Metodologi Penelitian Seni. Semarang: Cipta Prima Nusantara. Semarang: Cipta Prima Nusantara.

Sampurna, Angelia, Monica Tandian, Viviana Huang, Ruth Florescia Simanjuntak, and Rustono Farady Marta. 2020. "Implementasi Total Branding Dalam Perspektif Semiotika Pemasaran." CoverAge: Journal of Strategic $\begin{array}{llll}\text { Communication } & 10 & \text { (2): } & 59-73 .\end{array}$ doi:10.35814/coverage.v10i2.1384.

Tim Cheung, CNN. 2017. "Our Pick: World's 50 Best

Foods." https://edition.cnn.com/travel/article/worldbest-foods-readers-choice/index.html. 